\title{
Impact of nicotinamide mononucleotide on transplanted mouse ovarian tissue
}

\author{
Michael J Bertoldo,2, Valentina Rodriguez Paris@1, Debra A Gook ${ }^{3},{ }^{1}$ Melissa C Edwards ${ }^{1}$, \\ Katherine $\mathrm{Wu}^{1}$, Cai Jun Jean Liang ${ }^{1}$, Maria B Marinova ${ }^{1,2}$, Lindsay E Wu ${ }^{2}$, Kirsty A Walters ${ }^{1}$ and \\ Robert B Gilchrist ${ }^{1}$ \\ ${ }^{1}$ Fertility and Research Centre, School of Women's and Children's Health, University of New South Wales Sydney, \\ New South Wales, Australia, ${ }^{2}$ Laboratory for Ageing Research, School of Medical Sciences, University of New South \\ Wales Sydney, New South Wales, Australia and ${ }^{3}$ Reproductive Services, Royal Women's Hospital, Melbourne IVF, \\ Melbourne, Victoria, Australia
}

Correspondence should be addressed to R B Gilchrist; Email: r.gilchrist@unsw.edu.au

\begin{abstract}
Ovarian tissue cryopreservation and future transplantation is the only strategy to preserve the fertility of young female adolescent and prepubertal patients. The primary challenge to ovarian graft longevity is the substantial loss of primordial follicles during the period of ischaemia post-transplantation. Nicotinamide mononucleotide (NMN), a precursor of the essential metabolite $\mathrm{NAD}^{+}$, is known to reduce ischaemic damage. Therefore, the objective of the current study was to assess the impact of short- and long-term NMN administration on follicle number and health following ovarian tissue transplantation. Hemi-ovaries from C57Bl6 mice ( $n=8-12$ / group) were transplanted under the kidney capsule of bilaterally ovariectomised severe combined immunodeficient (SCID) mice. Recipient mice were administered either normal drinking water or water supplemented with NMN (2 g/L) for either 14 or 56 days. At the end of each treatment period, ovarian transplants were collected. There was no effect of NMN on the resumption of oestrous or length of oestrous cycles. Transplantation significantly reduced the total number of follicles with the greatest impact observed at the primordial follicle stage. We report that NMN did not prevent this loss. While NMN did not significantly impact the proportion of apoptotic follicles, NMN normalised PCNA expression at the primordial and intermediate stages but not at later stages. In conclusion, NMN administration did not prevent ovarian follicle loss under the conditions of this study.

Reproduction (2021) $161215-226$
\end{abstract}

\section{Introduction}

Advances in oncology have resulted in dramatically enhanced survival for cancer patients. However, cytotoxic cancer therapies such as ionising radiation and chemotherapy can seriously damage the ovaries of both children and those of reproductive age, leading to premature ovarian failure and consequently a loss of reproductive and endocrine function, a condition with serious long-term hormone-related health outcomes and infertility (Jeruss \& Woodruff 2009, Anderson \& Wallace 2011).

Fertility preservation is a series of clinical approaches that are targeted to preserve or protect the fertility of cancer patients. Current fertility preservation methods include oocyte and embryo cryopreservation, and ovarian tissue cryopreservation for future transplantation (Jeruss \& Woodruff 2009, Anderson \& Wallace 2011, De Vos et al. 2014, Anderson et al. 2015). However, oocyte collection using IVF procedures requires the injection of gonadotrophins and is, therefore, contraindicated in girls as well as in adult patients with hormone-sensitive cancers and those who do not have time to delay cancer treatment. For these patients, ovarian tissue cryopreservation is the only option currently available (Jeruss \& Woodruff 2009, Anderson et al. 2015).

Ovarian tissue cryopreservation and transplantation has proven to be an effective clinical procedure with approximately 130 births to date (Donnez \& Dolmans 2017 ) and over $90 \%$ return of ovarian function in graft recipients (Donnez \& Dolmans 2014, Meirow et al. 2014, Stoop et al. 2014). Ovarian tissue cryopreservation and transplantation is a multistep process that leads to a decline in follicle numbers (Amorim et al. 2011, Gavish et al. 2014, Ayunandari et al. 2016, Gavish et al. 2018, Roness \& Meirow 2019). The initial removal of ovarian tissue from its physical environment and blood and oxygen supply instigates a deleterious ischaemic cascade of events leading to follicle loss (McCord 1985, Van Eyck et al. 2010, Bertoldo et al. 2016b, Zhang et al. 2017, Roness \& Meirow 2019). This precedes physical 
and chemical insults in preparation for and during the cryopreservation and thawing process (Donnez \& Dolmans 2010, Lee et al. 2016). Additional factors such as graft size, transplantation site and initial ovarian reserve impact the extent of follicle loss (Gavish et al. 2014, Roness \& Meirow 2019). A diminished ovarian reserve in the graft potentially reduces the long-term endocrine function and reproductive potential of the graft, requiring additional transplantations of tissue from a valuable and limited supply.

Of the multiple steps involved in a cryopreservation and transplantation procedure, transplantation of ovarian tissue causes the most significant insult to follicle numbers (Amorim et al. 2011, Gavish et al. 2018, Roness \& Meirow 2019). The period immediately post-transplantation is characterised by ischaemia and an acute loss of both growing and primordial follicles with only $5-30 \%$ of primordial follicles surviving the grafting process (Baird et al. 1999, Liu et al. 2002, Dolmans et al. 2007, Amorim et al. 2011, Gavish et al. 2018). Furthermore, ischaemia promotes fibrosis and is a threat to graft survival (Dath et al. 2010). In order to reinstate blood supply, neoangiogenesis takes approximately 3-5 days (Martinez-Madrid et al. 2009, Van Eyck et al. 2009). During this time, a significant proportion of primordial follicles activate, leading to an increase in the proportion of growing follicles and proliferation of granulosa cells (Amorim et al. 2011, Gavish et al. 2014, 2018). Follicle survival depends on rescuing the tissue from ischaemia and hypoxia with neovascularisation. Therefore, strategies to enhance the quality of transplanted ovarian tissue are required to improve fertility preservation outcomes for cancer patients.

Nicotinamide adenine dinucleotide $\left(\mathrm{NAD}^{+}\right)$is an essential cellular cofactor involved in several critical cell functions including redox reactions, ATP generation, DNA repair and genome stability (Canto et al. 2015, Bonkowski \& Sinclair 2016). In mammals, $\mathrm{NAD}^{+}$is synthesised by four biosynthetic pathways, including de novo synthesis from tryptophan, the Preiss-Handler pathway from nicotinic acid, the nicotinamide riboside pathway using nicotinamide riboside, or conversion from nicotinamide in the salvage pathway (Canto et al. 2015, Fang et al. 2017). Synthesis of $\mathrm{NAD}^{+}$via the salvage pathway is the cell's primary source of $\mathrm{NAD}^{+}$, involving the conversion of nicotinamide to nicotinamide mononucleotide $(\mathrm{NMN})$ via the action of nicotinamide phosphoribosyltransferase (NAMPT), which is then, in turn, catalysed to $\mathrm{NAD}^{+}$by nicotinamide mononucleotide adenylyltransferase (NMNAT) (Mori et al. 2014, Fang et al. 2017). NMN, the rate-limiting intermediate of the salvage pathway, has gained significant attention as a NAD-boosting molecule with therapeutic potential (Rajman et al. 2018).

It is well established that levels of $\mathrm{NAD}^{+}$decline during ischaemic injury (Yamamoto et al. 2014,
Park et al. 2016). To maintain $\mathrm{NAD}^{+}$levels following ischaemic injury, $\mathrm{NAD}^{+}$consuming processes can be inhibited, or $\mathrm{NAD}^{+}$generating processes enhanced via the salvage pathway using the $\mathrm{NAD}^{+}$precursor $\mathrm{NMN}$. Administration of NMN protected heart tissue (Yamamoto et al. 2014), muscle (Das et al. 2018) and prevented brain damage (Park et al. 2016) from ischaemic insult. Furthermore, we and others recently demonstrated that $\mathrm{NAD}^{+}$precursor administration to mice reversed age-induced reductions in oocyte quality and fertility (Bertoldo et al. 2020, Miao et al. 2020, Yang et al. 2020). Taken together, these data suggest that NMN administration could enhance ovarian graft outcomes. Since NAMPT is a ratelimiting enzyme in the salvage pathway that results in depressed levels of NMN, we hypothesised that NMN administration could preserve follicle numbers in grafts of ovarian tissue. The aim of the present study is to assess the efficacy of NMN as a clinically relevant strategy to preserve follicle populations in ovarian tissue transplants.

\section{Materials and methods}

\section{Mice}

All animal experiments were approved by the University of New South Wales (UNSW) Animal Ethics Committee. UNSW AEC operates under animal ethics guidelines from the National Health and Medical Research Council (NHMRC) of Australia. Female C57Bl/6 mice were purchased from Australian Bio-Resources (ABR; Moss Vale, NSW, Australia). Female severe combined immunodeficient (SCID) mice were purchased from Animal Resources Centre (ARC; Perth, WA, Australia). Animals were maintained in ventilated cages at $22^{\circ} \mathrm{C}$ and $80 \%$ humidity at a density of up to 5 per cage, with access to food and water ad libitum. All water in this animal house was acidified to $\mathrm{pH} 3$ with $\mathrm{HCl}$ to decrease microbial growth. NMN (GeneHarbor Biotechnology, Hong Kong, China) was added to drinking water at $2 \mathrm{~g} / \mathrm{L}$ as previously described (Bertoldo et al. 2020). The UNSW Lowy Animal Facility maintained a $12 \mathrm{~h}$ light: $12 \mathrm{~h}$ darkness cycle with lights on at 07:00 h and off at 19:00 h. Twenty-four hours before surgery, recipient SCID females were randomly allocated to two groups and provided either standard water or water supplemented with NMN. Two experiments were conducted with differing durations of NMN treatment; for 14 days (Experiment 1); and for 56 days (Experiment 2). Schematic descriptions of the experiments are shown in Fig. 1. Given revascularisation of ovarian tissue occurs over a period of 3-5 days (Martinez-Madrid et al. 2009, Van Eyck et al. 2009), and a previous study had demonstrated that follicle development in transplanted tissue could be modulated 7 days after transplantation (Gao et al. 2013), the initial timepoint of 14 days was selected to allow grafted tissue to undergo two oestrous cycles before assessing follicle numbers. The second timepoint of 56 days was selected to assess long-term effects on follicle 
A

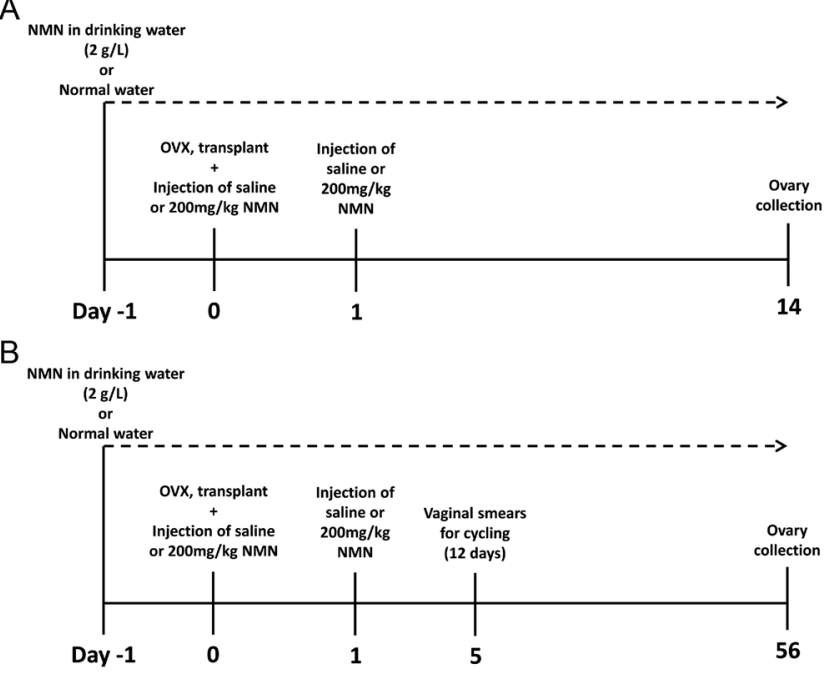

Figure 1 Schematic of Experiment 1 (A) examining the effect of 14 days of NMN treatment, and Experiment 2 (B) with 56 days of NMN treatment. In both experiments, hemi-ovaries from adult (6 weeks old) female C57Bl6 mice were transplanted without prior cryopreservation under the kidney capsule of recipient adult (10-week-old) SCID mice, or were immediately fixed (day 0 non-transplanted control). On the day before surgery (day -1) SCID mice were randomly allocated to either normal water (control) or NMN (2 g/L) in drinking water, and treatments were maintained for 14 days (Experiment 1 ; A) or 56 days (Experiment 2; B). At the conclusion of surgery (day 0 ) and the day after surgery (day 1 ) recipient mice received an i.p. injection of either saline or NMN (200 $\mathrm{mg} / \mathrm{kg}$ ). Ovaries were collected after 14 (A) or 56 (B) days.

development and to our knowledge, there were no previous reports reliably assessing transplanted mouse tissue past 3 weeks post-transplantation.

\section{Ovarian tissue collection}

Donor C57Bl/6 mice (4-6 weeks of age) were sacrificed by cervical dislocation. Ovaries were collected and placed into HEPES-buffered $\alpha$ MEM (GIBCO Life Technologies) handling medium supplemented with $3 \mathrm{mg} / \mathrm{mL}$ BSA (Sigma Aldrich). Under a dissecting microscope each ovary was trimmed of excess tissue and cut in half using a razor blade. Of the four hemi-ovaries from each donor animal, one was randomly allocated to fixation in $4 \%$ PFA overnight at $4{ }^{\circ} \mathrm{C}$ representing the day 0 non-transplanted control, another two randomly allocated to either the control group or NMN group (see next section), and the fourth hemi-ovary was discarded. Eleven donors and 22 recipients were used in Experiment 1, and 8 donors and 16 recipients in Experiment 2.

\section{Ovariectomy and transplantation into SCID mice}

All surgeries were performed on warming mats set at $37^{\circ} \mathrm{C}$. To perform bilateral ovariectomies, recipient SCID mice (8-10 weeks old) were anaesthetised with $2.5-3 \%$ isoflurane (Henry Schein, Mascot, Australia) administered via a nose cone. A single injection of carprofen ( $5 \mathrm{mg} / \mathrm{kg}$; Carprieve, Norbrook) in sterile saline was administered as analgesic. An abdominal lateral incision at the level of the kidney was made, the wall of the abdomen and peritoneum opened, and the ovary and uterine horn exteriorised. The ovarian vasculature was tied off and restricted with an $8-0$ silk suture (Ethicon, Puerto Rico, USA), the ovary removed, and the reproductive tract returned to its normal anatomical position. The peritoneum was sutured closed with 6-guage suture and abdominal wall closed with either a 4-0 silk suture or $7 \mathrm{~mm}$ Michel clips (CellPoint Scientific, Maryland, USA). On the contralateral side, the same process was repeated, however, before closing the peritoneum and abdominal wall, the kidney was exposed, and a small tear was made in the kidney capsule. A piece of ovarian tissue was randomly selected and inserted under the kidney capsule as previously described (Gook et al. 2001). The peritoneum and abdominal wall were then closed and the mouse administered either $100 \mu \mathrm{L}$ of saline (control group) or NMN (200 mg/kg in $100 \mu \mathrm{L}$ of saline) (Ho et al. 2017, Marinova et al. 2020) and placed in a warmed cage to recover. All procedures were performed under aseptic conditions. Twenty-four hours after surgery, mice were administered a second injection of saline or NMN. The intraperitoneal injections were administered in the first $24 \mathrm{~h}$ to provide sufficient NMN directly into the peritoneum as an alternative route of NMN administration for ovarian tissue protection as previously described (Ho et al. 2017, Marinova et al. 2020).

\section{Assessment of the oestrous cycle}

In Experiment 2, oestrous cycle stage was determined from vaginal epithelial cell smears taken daily for 12 consecutive days, commencing on day 5 post-surgery (Fig. 1). Smears were collected using $15 \mu \mathrm{L}$ of $0.9 \%$ sterile saline and transferred to glass slides to air dry. Dry smears were stained with $0.5 \%$ toluidine blue before being examined under a light microscope. Oestrous cycle stage was determined based on the presence or absence of leukocytes, cornified epithelial cells, and nucleated epithelial cells. Proestrus was characterised by the presence of mostly nucleated and some cornified epithelial cells; oestrus was identified by the presence of primarily cornified epithelial cells; at metoestrus both cornified epithelial cells and leukocytes were present; and at dioestrus predominantly leukocytes were present.

\section{Graft recovery and histological assessment}

At the end of the treatment period (Experiment 1, 14 days; Experiment 2, 56 days), SCID mice were anesthetised using $3 \%$ isoflurane via a nose cone. Mice were then killed by cervical dislocation and the entire kidney with the graft was recovered and fixed in $4 \%$ PFA overnight at $4{ }^{\circ} \mathrm{C}$. The next day the majority of the renal tissue was removed using a scalpel being cautious not to disturb the graft, with the graft then stored in $70 \%$ ethanol before histological processing. The entire graft with remaining renal tissue was then embedded in paraffin and cut into serial sections, $5 \mu \mathrm{m}$ in thickness. Every 10th serial section was stained with haematoxylin and eosin (H\&E) and observed with light microscopy to perform 
histomorphologic assessments. The remaining sections were kept for immunohistochemical staining. Ovarian follicles were classified as primordial, intermediate, primary, secondary and antral, following standard criteria (Myers et al. 2004, Bertoldo et al. 2016a). Primordial follicles were characterised by one oocyte surrounded by a single layer of flattened pre-granulosa cells. Intermediate follicles consisted of an oocyte surrounded by a single layer of flattened and cuboidal granulosa cells. In primary follicles, oocytes were surrounded by at least one complete layer of cuboidal granulosa cells. Secondary follicles contained at least two complete layers of cuboidal granulosa cells. Antral follicles were characterised by the development of an antral cavity. At least 134 and 69 sections were assessed for Experiments 1 and 2 , respectively.

To evaluate the effect of transplantation and NMN on oocyte and follicle growth, oocyte and follicle diameters were calculated from the mean of two perpendicular measurements using the computer-based image analysis program Image Software (NIH, USA). The boundary of the follicle was defined as the basement membrane, clearly visible as a demarcation between the granulosa cells and the surrounding theca/stroma. Only follicles completely free of any sign of atresia such as pyknotic cells were analysed for morphometric assessments. All histological assessments were performed blinded by two independent observers.

\section{Immunohistochemistry and image analysis}

Tissue was deparaffinised in xylene, rehydrated and endogenous peroxidases blocked with $1.2 \%$ hydrogen peroxide. Sections were then blocked with $1 \%$ fetal bovine serum (FBS; GIBCO) and washed in PBS. Those sections destined for analysis of caspase-3 expression were subjected to heat-induced antigen retrieval using sodium citrate (Vector Labs H3300). Sections were incubated overnight at $4{ }^{\circ} \mathrm{C}$ in a humidified chamber with either rabbit anticaspase-3 (diluted 1:400 in PBS + 1\% FBS; Abcam, ab13847) or rabbit anti-PCNA (diluted 1:400 in PBS + 1\% FBS; Sigma, $\mathrm{SAB} 2108448)$. Sections were washed three times in PBS and then incubated with goat anti-rabbit peroxidaseconjugated secondary antibody (Jackson Immunoresearch Laboratories, cat\# 111-035-144) diluted 1:800 in PBS with $0.1 \%$ BSA at room temperature for $4 \mathrm{~h}$ in a humidified chamber. Immunostaining was developed by using DAB substrate (Vector Labs) as a chromogen for $70 \mathrm{~s}$. Doxorubicin (Cayman Chemical) treated mouse ovarian tissue and paraffin-embedded mouse intestinal tissue were used as positive controls for caspase-3 and PCNA, respectively. Rabbit isotope control IgG (Abcam, ab172730) in place of the primary antibody served as a negative control. All samples were processed at the same time to prevent interreplicate variation in staining. Images were captured with a computer-based program (Olympus DP Controller, Olympus Optical Japan) and analysed using ImageJ Software. The proportion of caspase-3 immunopositive granulosa cell area was calculated as a percentage of total antral follicle area and evaluated through colour segmentation analysis, which identifies objects by locating all objects of a specific colour (brown stain for DAB chromagen), as described previously (Ortega et al. 2009, Bertoldo et al. 2019). To assess only granulosa cell caspase-3 protein expression, the oocyte and antral cavity were digitally removed from the images before analysis. PCNA expression was calculated as a proportion of label-positive granulosa cells from the total granulosa cell number within each follicle (Salvetti et al. 2012). Sections were analysed with the observer blinded to treatment.

\section{Follicle health}

In Experiment 2, the extended time period resulted in insufficient numbers of follicles to adequately assess PCNA and cleaved caspase-3. Therefore, as an alternative to evaluate follicle health, we assessed the proportion of pyknotic granulosa cells which requires far fewer follicles than would otherwise be required for immunohistochemistry. Unhealthy primary, secondary and antral follicles were classified according to strict morphometric criteria if they contained a degenerate oocyte, disorganised granulosa cells layers and/ or more than $10 \%$ of the granulosa cells being pyknotic in appearance, as previously described (Walters et al. 2007). The proportion of unhealthy follicles in each graft was calculated as the percentage of all follicles at that developmental stage. All health assessments were performed blinded

\section{Statistical analysis}

Differences in the total number of follicles were analysed by one-way ANOVA followed by a Tukey's multiple comparison test. Differences in the proportion of growing vs non-growing and proportion of follicles at each stage were analysed using a Kruskal-Wallis test following arcsine transformation of percentage data. Oocyte and follicle diameters and the oocyte:follicle ratio were analysed using either one-way ANOVA followed by a Tukey's post hoc test or a KruskalWallis test. PCNA and cleaved caspase-3 expression was analysed using a Kruskal-Wallis test followed by a Dunn's post hoc test. Oestrous cycling data were analysed using a MannWhitney test, while differences in the proportion of unhealthy follicles were analysed by $\chi^{2}$. Statistical differences $P<0.05$ were considered significant. Data are shown in figures as mean $\pm 95 \% \mathrm{Cl}$.

\section{Results}

\section{Experiment 1}

\section{Follicle distributions}

At least 134 sections in each group were assessed for follicle distribution data. Fourteen days after transplantation overall ovarian graft morphology was grossly similar in both transplanted groups. Grafted tissue in the control and NMN groups contained significantly fewer follicles compared to fresh tissue $(P<0.001)$, with no significant differences between transplant groups (Fig. 2A and Supplementary Fig. 1A, see section on supplementary materials given at the end of this article). 

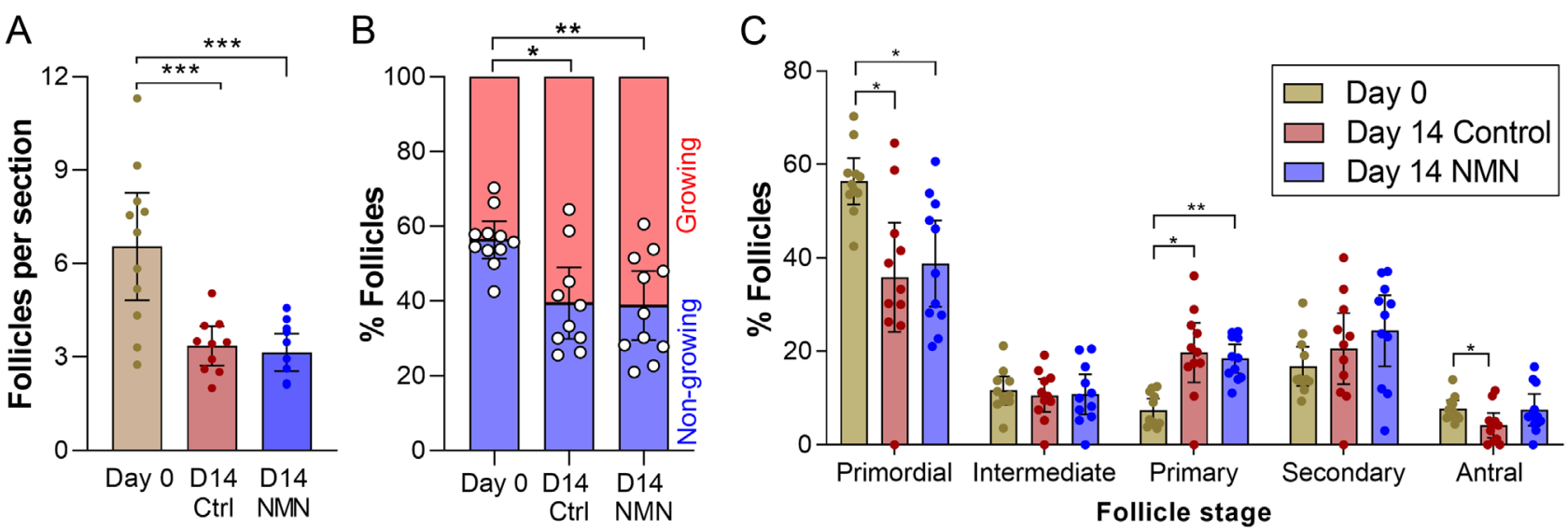

Figure 2 Follicle numbers and the proportion of growing follicles in day 0 non-transplanted control ovaries and in ovarian grafts in recipients administered either normal water or water supplemented with NMN (2 g/L). On day 14 (D14) ovarian transplants were collected and (A) follicle number per section, (B) the proportion of non-growing and growing follicles, and (C) the proportion of follicles at each stage of follicle development were determined and compared to day 0 non-transplanted tissue from the same animals. Data are presented as mean $\pm 95 \% \mathrm{Cl}$ (A, C). Number of hemi-ovaries assessed $=11$ per treatment. ${ }^{* * *} P<0.0001 ; * * P<0.001 ; * P<0.05$.

The proportion of non-growing and growing follicles in non- and transplanted tissue are presented in Fig. 2B. All grafts exhibited significant increases in growing follicles compared to fresh tissue $(P<0.05)$. When follicles were classified according to developmental stage, it was observed that a significant reduction in the proportion of primordial follicles in both transplanted groups was associated with a concomitant increase in the proportion of primary follicles (Fig. 2C; $P<0.05$ ), inferring that primordial follicle activation had taken place as a result of transplantation (Fig. 2C). At the antral stage, there was a small but significant reduction in the number of antral follicles in control transplanted tissue compared to non-transplanted tissue ( $P<0.05$; Fig. $2 \mathrm{C})$.

\section{Follicle morphometrics}

Oocyte and follicle diameter and the oocyte to follicle ratio were assessed. As presented in Fig. 3A, compared to day 0 tissue, there was a significant reduction in oocyte size in secondary follicles from both control and NMN grafted tissue $(P<0.0001)$, which was not observed in either primary or antral follicle stages. This was associated with a significant reduction in secondary follicle size (Fig. 3B). However, when follicles in grafted tissue reached the antral stage, they were significantly larger compared to antral follicles from day 0 fresh tissue $(P<0.05$; Fig. 3B). Consequently, the oocyte to follicle ratio of antral follicles was smaller in grafted tissue compared to fresh tissue (Fig. 3C). There were no effects of NMN treatment on oocyte or follicle size at any stage of follicle development, compared to control grafts (Fig. 3).

\section{Granulosa cell apoptosis and proliferation}

PCNA staining in an antral follicle from the NMN treatment is shown in Fig. 4A. Analysis of 548 follicles showed that transplantation led to a notable increase in PCNA expression at all stages of follicle development, compared to the day 0 non-transplanted control $(P<0.05$; Fig. 4B). While PCNA expression in grafts from NMN-treated animals, compared to control grafts, appeared to be more similar to that of fresh nontransplanted tissue at the primordial and intermediate stages $(P>0.05)$, primary, secondary and antral follicle PCNA expression in NMN-treated transplanted tissue was significantly greater $(P<0.05)$ than that of fresh tissue (Fig. 4B). A representative example of cleaved caspase-3 immunostaining in an antral follicle from the NMN treatment, is shown in Fig. 4C. Overall expression of cleaved caspase-3 (apoptosis) was broadly similar in both transplanted groups. Following analysis of 608 follicles, cleaved caspase-3 expression levels were similar between fresh non-transplanted and transplanted tissues treated with or without NMN, at all follicle stages (Fig. 4D).

\section{Experiment 2}

\section{Oestrous cycling}

Examples of oestrous cyclicity in females from each group are represented in Fig. 5A. Assessment of oestrous cycle resumption commenced 5 days after transplantation surgery and continued for 12 consecutive days. The recovery rate for oestrous cyclicity was $100 \%$ in both groups. Compared to the control group, there was no significant effect of NMN treatment on the period of time animals spent at each stage of the oestrous cycle (Fig. 5B), nor on cycle length (Fig. 5C).

\section{Follicle distributions}

At least 69 sections in each group were assessed for follicle distribution data. Fifty-six days after 

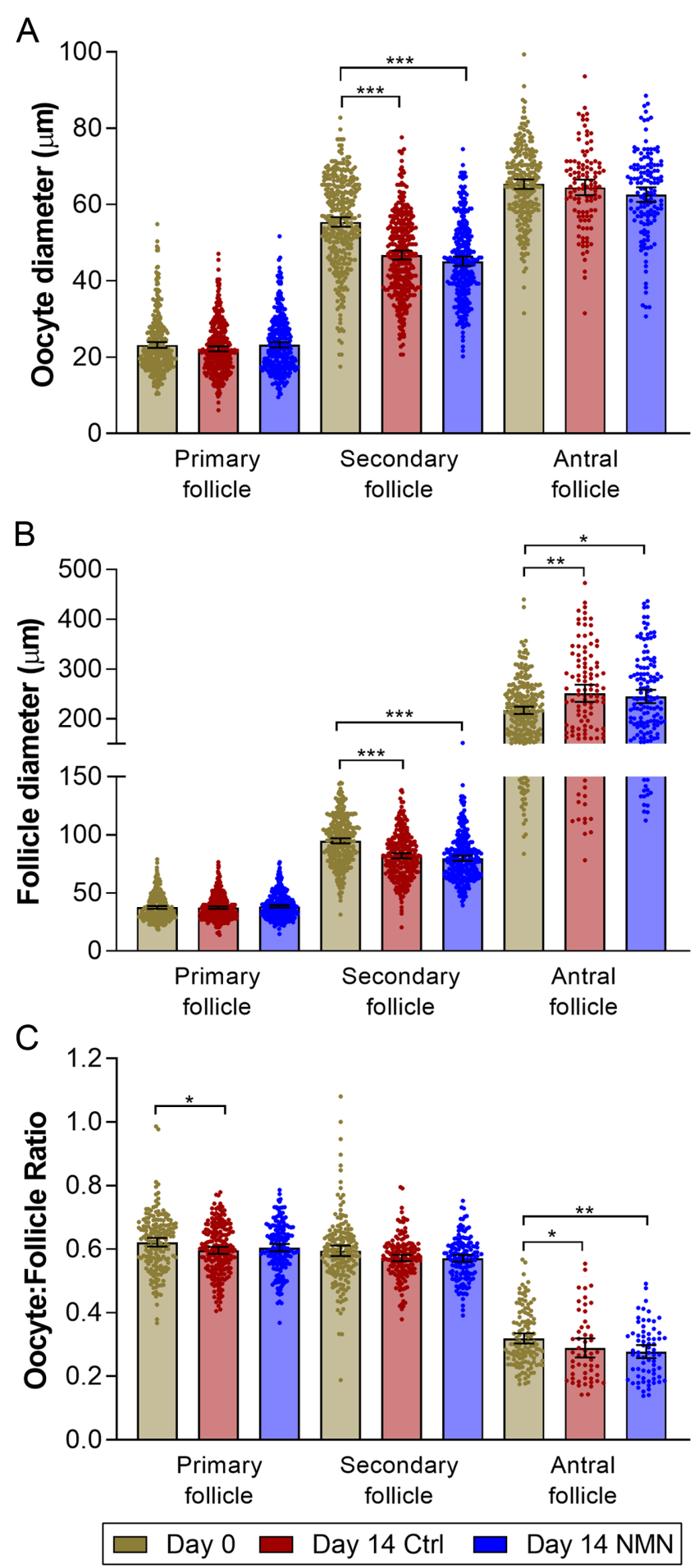

Figure 3 Oocyte and follicle diameter and oocyte:follicle ratio from primary, secondary and antral follicles in day 0 non-transplanted ovarian tissue compared to ovarian grafts in recipients administered either normal water or water supplemented with NMN (2 g/L). Day 0 or day 14 ovarian transplants were collected and (A) oocyte diameter, (B) follicle diameter and, (C) oocyte:follicle ratio at each stage were determined. Measurements were collected from 11 animals in each group. Data are presented as mean $\pm 95 \% \mathrm{Cl}$. ${ }^{* * *} P<0.0001$; ${ }^{* *} P<$ $0.001 ;{ }^{*} P<0.05$ transplantation, overall ovarian graft morphology was broadly similar in control and NMN-treated recipients. In general, the pattern of follicle loss as a result of transplantation and subsequent follicle development was similar to that of Experiment 1, but was more accentuated due to the extended period the grafts remained in vivo. Grafted tissue in the control and NMN groups contained significantly fewer follicles compared to day 0 fresh non-transplanted tissue $(P<0.001)$, and there was no significant difference between the transplant groups (Fig. 5D and Supplementary Fig. 1B). The proportion of non-growing and growing follicles in non-transplanted and transplanted tissues are presented in Fig. 5E. All grafts exhibited a significant increase in the proportion of growing follicles compared to the fresh non-transplanted tissue $(P<0.001$; Fig. 5E). Follicle developmental stage classification showed a substantial and significant $(P<0.0001)$ reduction in the proportion of primordial follicles in both transplanted groups, compared to the non-transplanted day 0 control, which was associated with a concomitant increase $(P<0.001)$ in the proportion of secondary and antral follicles, inferring transplantation led to the activation of primordial follicles and that follicle development had proceeded throughout the 56-day experiment (Fig. 5F).

\section{Follicle morphometrics and health}

As presented in Fig. 6A, oocyte diameter in primary and secondary follicles were similar between all groups. However, at the antral stage, NMN treatment of transplanted animals significantly $(P<0.001)$ reduced oocyte diameter compared to those in non-transplanted tissue $(P<0.001)$. There was no effect of transplantation or treatment of grafted animals with NMN on follicle diameter $(P>0.05$; Fig. 6B). The oocyte to follicle ratio of secondary and antral follicles was lower $(P<0.05)$ in grafted tissue, irrespective of NMN treatment, compared to fresh tissue (Fig. 6C).

To assess follicle health after 56 days of transplantation, the number of pyknotic granulosa cells were counted in primary, secondary and antral follicles, and compared to day 0 fresh non-transplanted tissue. There was no significant effect of transplantation or NMN treatment on the proportion of unhealthy follicles (Fig. 6D).

\section{Discussion}

Strategies to prevent follicle loss in transplanted ovarian tissue are required to enhance outcomes for this fertility preservation approach. In the present study, we investigated the potential for NMN administration to enhance ovarian tissue graft outcomes by preventing follicle loss in a mouse model. However, we report that NMN did not prevent follicle loss in transplanted tissue. 
A
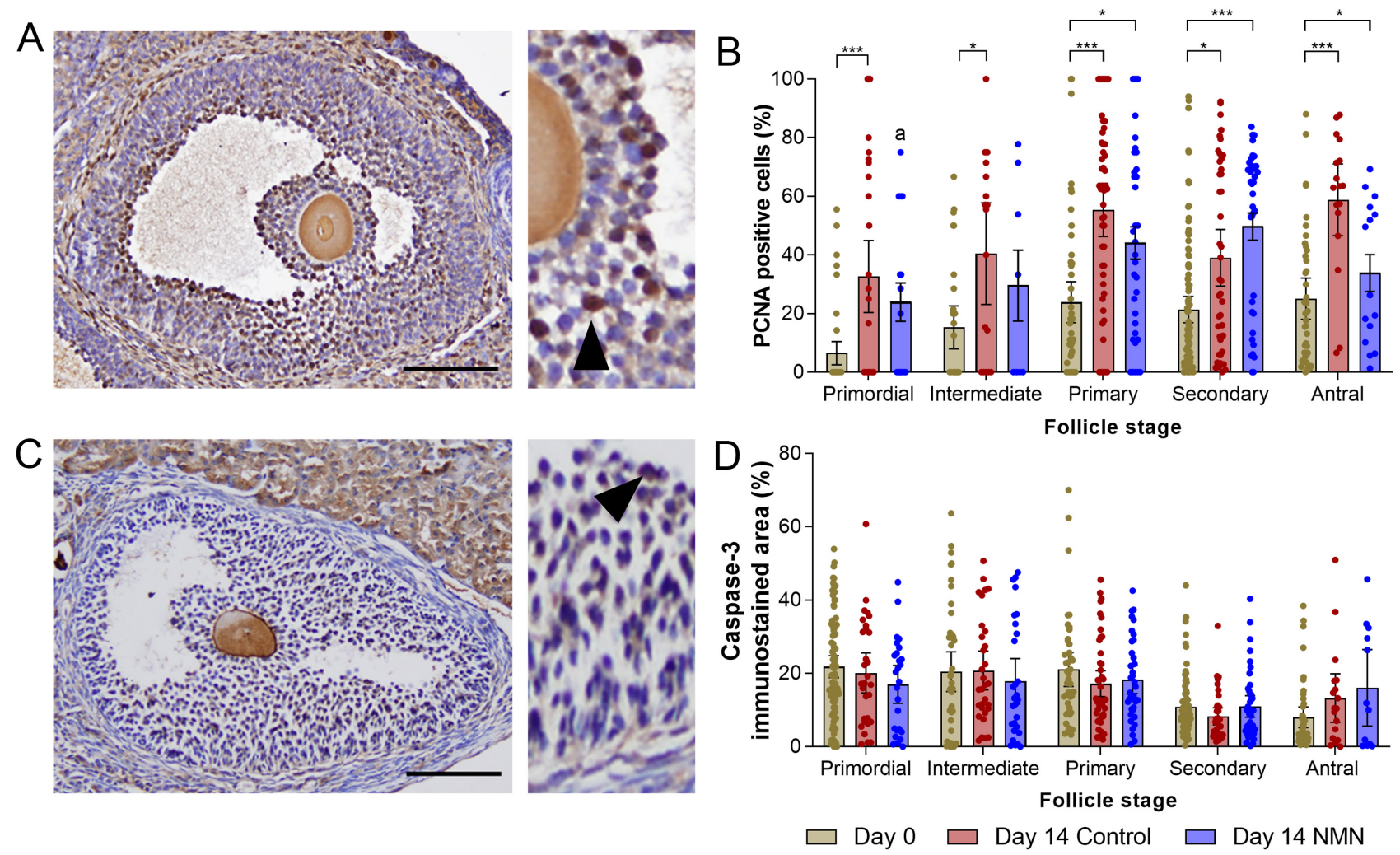

Figure 4 Granulosa cell proliferation and apoptosis in primordial, intermediate, primary, secondary and antral follicles on day 0 nontransplanted ovarian tissue, compared to ovarian grafts in recipients administered either normal water or water supplemented with $\mathrm{NMN}(2 \mathrm{~g} / \mathrm{L})$ for 14 days. (A) Representative images of PCNA expression, (B) the proportion of PCNA positive cell cells, (C) representative images of cleaved caspase-3 expression and (D) cleaved caspase-3 immunopositive area was calculated. Arrow heads identify representative positive cells for both PCNA and cleaved caspase-3. Data are presented as mean $\pm 95 \% \mathrm{Cl}$. ${ }^{* *} P<0.0001 ; * * P<0.001 ; * P<0.05 ; \mathrm{a}, 0.06$. Scale bar $=100 \mu \mathrm{m}$.

Declining cellular $\mathrm{NAD}^{+}$levels are a feature of ischaemia (Wang et al. 2011, Yamamoto et al. 2014, Park et al. 2016, Das et al. 2018). Previous animal studies have demonstrated that NMN treatment prevents ischaemic damage in the brain, heart and muscle, which is associated with reduced cell death and improved tissue function (Wang et al. 2011, Yamamoto et al. 2014, Park et al. 2016, Wei et al. 2017, Das et al. 2018). While the underlying mechanisms are unclear, some evidence suggests that the NMN-NAD-SIRT1 and NMN-NAD-PARP pathways play a key role in protecting against neural and cardiac ischemia (Wang et al. 2011, Yamamoto et al. 2014, Liang et al. 2015). Sirtuins, a family of protein deacylases, regulate many fundamental processes within cells including cell metabolism, DNA repair, maintenance of genome integrity, cellular senescence and inflammation (Rajman et al. 2018, Tatone et al. 2018), and are implicated in fertility (Di Emildio et al. 2014, Bertoldo et al. 2016b, 2020, Iljas et al. 2020). A second family of $\mathrm{NAD}^{+}$consuming enzymes are the poly-ADP-ribose polymerases (PARPs). The most understood member of the family, PARP1, plays a key role in the repair of single-strand DNA breaks resulting from oxidative stress. Paradoxically, PARPs also increase ischaemic damage (Endres et al. 1997, Cozzi et al. 2006), and when PARP1 function is disrupted, mice are resistant to cerebral ischaemia (Eliasson et al. 1997). Evidence suggests that PARP1 activity increases with decreasing $\mathrm{NAD}^{+}$concentration in mouse tissue, which was negated by NMN administration, suggesting that $\mathrm{NAD}^{+}$is consumed by PARP1 to repair tissue. However, NMN inhibited PARP1-dependent NAD ${ }^{+}$ catabolism (Park et al. 2016). Therefore, the inhibition of poly-ADP-ribose formation by NMN suggests that the protective mechanism is not due to an increase in $\mathrm{NAD}^{+}$availability via the salvage pathway, but rather inhibition of PARP1 activity following ischaemic insult (Park et al. 2016). We did not directly assess levels of ischaemia in grafted tissue. However, given we found that NMN did not impact follicle numbers or apoptosis, we surmise that $N M N$ administered systemically to recipients did not protect against ischaemic damage in grafted tissue. This contrasts with the previously described beneficial effects of NMN against ischaemic damage in other organs.

In the present study, we commenced NMN treatment (in drinking water) the day before surgery. At the 

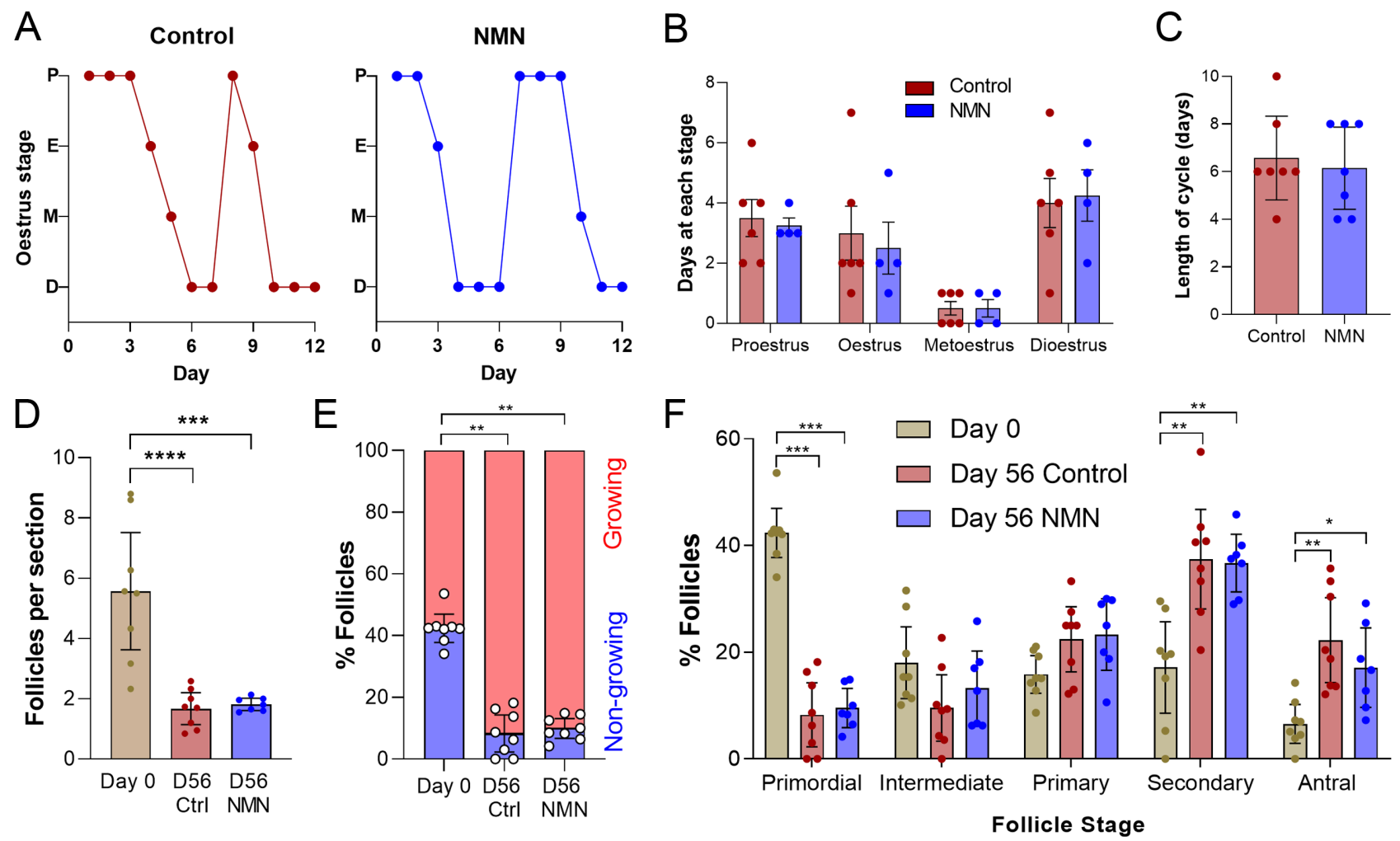

Figure 5 Effect of transplant and NMN on oestrous cycle and follicle development. Starting 5 days after transplantation surgery vaginal smears were taken for 12 days. (A) Representative oestrous cycles from control and NMN-treated recipient females, (B) the number of days at each cycle stage, and (C) average oestrous cycle length were assessed. On day 56 (D56) ovarian transplants were collected and (D) follicle number per section, (E) the proportion of non-growing and growing follicles, and (F) the proportion of follicles at each stage of follicle development were determined and compared to day 0 non-transplanted tissue. Data are presented as mean $\pm 95 \% \mathrm{Cl}(\mathrm{A}, \mathrm{B}, \mathrm{C}, \mathrm{E})$. Number of hemi-ovaries assessed $=8$ per treatment. ${ }^{* * * *} P<0.0001 ;{ }^{* * *} P<0.0001 ;{ }^{* *} P<0.001 ; * P<0.05$.

completion of surgery and the day after surgery, animals were administered an i.p. injection of NMN (200 mg/ $\mathrm{kg}$ ) as this regime has previously been shown to protect ovarian tissue against chemotherapy (Ho et al. 2017, Marinova et al. 2020). We did not confirm if NMN and $\mathrm{NAD}^{+}$levels were raised in grafted tissue, however, Yamamoto et al. (2014) demonstrated that i.p. injection of NMN $(500 \mathrm{mg} / \mathrm{kg})$ successfully increased NAD ${ }^{+}$ content in the heart within $30 \mathrm{~min}$, and that treatment with NMN 30 min before cardiac ischaemia avoided ischaemia-induced reductions in $\mathrm{NAD}^{+}$content in the heart, suggesting that i.p. administration of NMN enhances the amount of $\mathrm{NAD}^{+}$of the heart during ischaemia within a relatively short period (Yamamoto et al. 2014). While the model by Yamamoto et al. (2014) is different to the present study, whereby cardiac blood supply was cut-off then reinstated, whereas the present experimental model required neovascularistion between ovarian and renal tissue, it is possible that injecting recipient mice before surgery and with a larger dose may have yielded a different outcome and prevented follicle loss. Irrespective of the differences in treatment regimes, NMN treatment in the current study did not prevent follicle loss as a result of transplantation.
Recently, we were the first to demonstrate, in the context of reproductive ageing, a beneficial effect of NMN therapy on several readouts of fertility, including increased ovulation rate and litter size, suggesting that NMN modulates follicle development (Bertoldo et al. 2020). These initial findings were independently validated (Miao et al. 2020, Yang et al. 2020), and together drive significant interest in the broader potential application of $\mathrm{NAD}^{+}$boosting compounds in reproductive medicine, and in the case of the present study, investigating the potential benefit of increasing cellular $\mathrm{NAD}^{+}$to mitigate against follicle loss in ovarian tissue grafts. However, recently, Stringer et al. (2020) reported that NMN failed to protect against depletion of the ovarian reserve following cancer treatment. In that study, which aimed to determine whether supplementation of $\mathrm{NMN}$ could preserve the ovarian reserve in intact animals following $\gamma$-irradiation or cyclophosamide treatment, NMN treatment was provided 7 days before cancer treatment and then stopped the day after cancer treatment, precisely when we would predict the greatest support for $\mathrm{NAD}^{+}$synthesis is needed to protect the ovary. Therefore, it is not unexpected that NMN did not provide protection to the ovarian reserve in that study. 


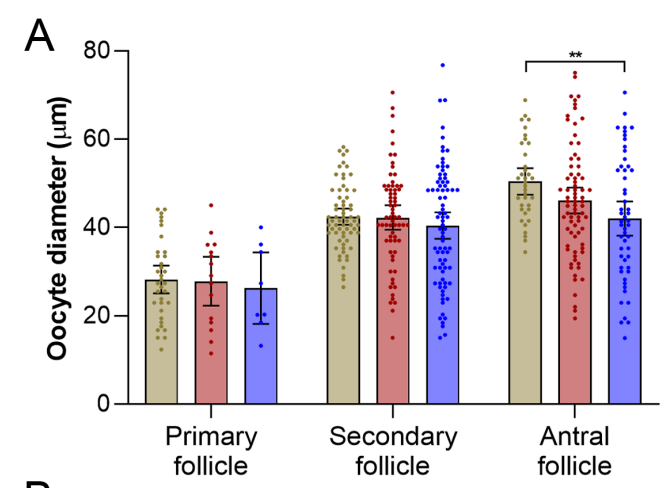

\section{B}
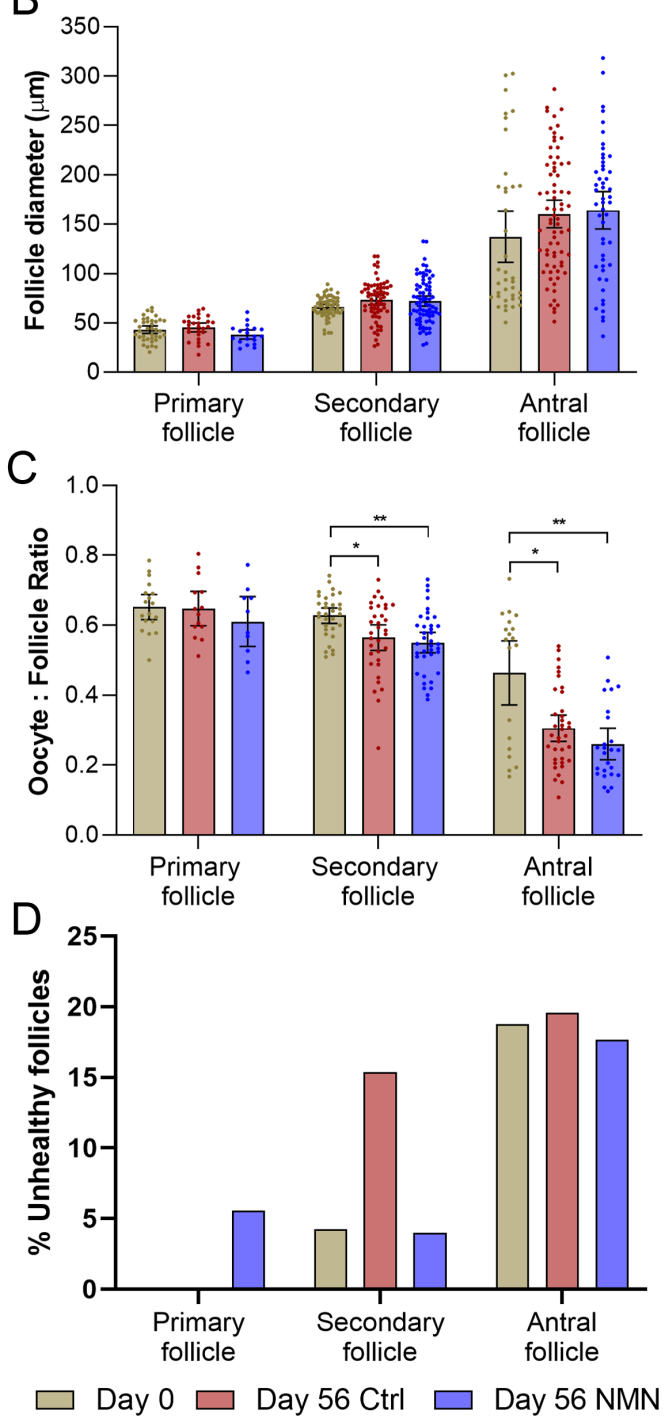

Figure 6 Oocyte and follicle diameter and oocyte:follicle ratio from primary, secondary and antral follicles in day 0 non-transplanted ovarian tissue compared to ovarian grafts in recipients administered either normal water or water supplemented with NMN (2 g/L). Grafts were recovered 56 days after surgery and the (A) oocyte diameter, (B) follicle diameter, (C) oocyte:follicle ratio and, (D) proportion of unhealthy follicles at each stage of follicle development were determined. Data are presented as mean $\pm 95 \% \mathrm{Cl}(\mathrm{A}, \mathrm{B}, \mathrm{C}) .{ }^{*} \mathrm{P}<$ $0.001 ; * P<0.05$.
This contrasts with the present study where we supplied NMN before and after surgery. However, it is possible that we did not administer NMN long enough prior to surgery as we previously demonstrated that NMN supplied in drinking water 3 days before doxorubicin and cisplatin treatment and continued for a further 8 weeks, protected against depletion of the ovarian reserve (Ho et al. 2017, Marinova et al. 2020). Taken together, this implies that for NMN to provide a protective effect, a sufficient period of time before and after insult (grafting or chemotherapy) is required.

Indeed, the age of the donors may have contributed to the results of the present study since tissue from young animals is perhaps refractory to ischemia. However, follicle loss following ovarian tissue transplantation occurs even when transplanted tissue originates from young (13-26 years) patients (Gavish et al. 2018) and young mice at similar ages to the donors in the present study (Mahmoodi et al. 2015). Ischemic damage also occurs in ovaries of prepubertal rodents (Usta et al. 2008, Tuncer et al. 2016), suggesting that ischemia occurs at all ages.

Given we observed minimal effects of NMN on follicle number and health, a potential concern is that our graft technique is not adequate. However, this is unlikely for two primary reasons. First, 100\% of the graft recipients, which had none of their own ovarian tissue as they were ovariectomised, exhibited resumption of oestrous cyclicity and with cycles of the correct length. Secondly, 14 days after transplantation, the reduction in the proportion of primordial follicles was associated with a concomitant increase in primary follicles only, and after 56 days, a concomitant increase in secondary and antral follicles was observed. Taken together, these observations demonstrate that the grafts were able to support follicle development through to the antral stage with an associated resumption of systemic endocrine function, and therefore the grafts were functional and could be expected to be responsive to interventions. Alternatively, high endogenous levels of renal $\mathrm{NAD}^{+}$ and $\mathrm{NMN}$ may also have impacted graft outcomes (Mori et al. 2014), thereby masking any beneficial effect of NMN administration.

In conclusion, the current study has shown that the NMN treatment regimes described do not prevent follicle loss in ovarian tissue grafts from adult C57BI/6 mice. We also demonstrated that NMN does not appear to greatly impact follicle health or viability. The observation that at 14 days post-surgery, secondary follicles in transplanted tissue were smaller than those in fresh tissue but at the antral stage are larger than fresh tissue, may suggest a level of asynchrony in granulosa cell proliferation (Smitz \& Cortvrindt 2002) and subsequent compensatory development. Given ovarian tissue transplantation and the preceding period of ischaemia is a significant insult to tissue viability, 
the treatment regimes in the present study may have to be adapted to better protect tissue. Nonetheless, further research is required to determine if modifying the dose or mode of administration of $\mathrm{NAD}^{+}$boosting compounds will protect the ovarian reserve from insult during transplantation.

\section{Supplementary materials}

This is linked to the online version of the paper at https://do i.org/10.1530/REP-20-0539.

\section{Declaration of interest}

The salary of $M B$ in the labs of R B G and LE W was partly supported by sponsored research from Jumpstart Fertility Pty Ltd. L E W is a founder, shareholder and director of Jumpstart Fertility. He is also a consultant to the Life Biosciences group, and is a scientific advisor and shareholder to Metro Biotech, a member of the EdenRoc group, and to Intravital Pty Ltd. R B $\mathrm{G}$ is a consultant to City Fertility Centre Global Pty Ltd. Robert Gilchrist is on the editorial board of Reproduction. Robert Gilchrist was not involved in the review or editorial process for this paper, on which he is listed as an author.

\section{Funding}

This work was supported by a Project Grant (APP1139763) and Fellowships (APP1117538, APP1127821) from the National Health and Medical Research Council of Australia, and by sponsored research from Jumpstart Fertility Pty Ltd.

\section{Author contribution statement}

M J B, R B G and K A W conceived and planned the study. M J B, V R P, D A G, M C E, K W, C J J L and M B M performed experiments. M J B, LEW analysed data and prepared figures. M J B, R B G and K A W wrote and edited the manuscript. R B G, LE W and K A W funded the study.

\section{Acknowledgements}

The authors gratefully acknowledge the assistance of Eva Sinha, Chloe Wai Sum Ho and Amy Ngov.

\section{References}

Amorim CA, David A, Dolmans MM, Camboni A, Donnez J \& Van Langendonckt A 2011 Impact of freezing and thawing of human ovarian tissue on follicular growth after long-term xenotransplantation. Journal of Assisted Reproduction and Genetics 28 1157-1165. (https://doi. org/10.1007/s10815-011-9672-z)

Anderson RA \& Wallace WHB 2011 Fertility preservation in girls and young women. Clinical Endocrinology 75 409-419. (https://doi.org/10.1111/ j.1365-2265.2011.04100.x)

Anderson RA, Mitchell RT, Kelsey TW, Spears N, Telfer EE \& Wallace WHB 2015 Cancer treatment and gonadal function: experimental and established strategies for fertility preservation in children and young adults. Lancet: Diabetes and Endocrinology 3 556-567. (https://doi. org/10.1016/S2213-8587(15)00039-X)

Ayunandari S, Winkler-Crepaz K, Paulitsch M, Wagner C, Zavadil C, Manzi C, Ziehr SC, Wildt L \& Hofer-Tollinger S 2016 Follicular growth after xenotransplantation of cryopreserved/thawed human ovarian tissue in SCID mice: dynamics and molecular aspects. Journal of Assisted Reproduction and Genetics 33 1585-1593. (https://doi.org/10.1007/ s10815-016-0769-2)

Baird DT, Webb R, Campbell BK, Harkness LM \& Gosden RG 1999 Longterm ovarian function in sheep after ovariectomy and transplantation of autografts stored at -196C. Endocrinology 140 462-471. (https://doi. org/10.1210/endo.140.1.6453)

Bertoldo MJ, Bernard J, Duffard N, Tsikis G, Alves S, Calais L, Uzbekova S, Monniaux D, Mermillod P \& Locatelli Y 2016a Inhibitors of c-jun phosphorylation impede ovine primordial follicle activation. Molecular Human Reproduction 22 338-349. (https://doi.org/10.1093/molehr/ gaw012)

Bertoldo MJ, Guibert E, Faure M, Guillou F, Rame C, Nadal-Desbarats L, Foretz M, Viollet B, Dupont J \& Froment P 2016b Specific deletion of AMP-activated protein kinase ( $\alpha 1 \mathrm{AMPK})$ in mouse Sertoli cells modifies germ cell quality. Molecular and Cellular Endocrinology 423 96-112. (https://doi.org/10.1016/j.mce.2016.01.001)

Bertoldo MJ, Caldwell ASL, Riepsamen AH, Lin D, Gonzalez MB, Robker RL, Ledger WL, Gilchrist RB, Handelsman DJ \& Walters KA 2019 A hyperandrogenic environment causes intrinsic defects that are detrimental to follicular dynamics in a PCOS mouse model. Endocrinology 160 699-715. (https://doi.org/10.1210/en.2018-00966)

Bertoldo MJ, Listijono DR, Ho W-HJ, Riepsamen AH, Goss DM, Richani D, Jin XL, Mahbub S, Campbell JM, Habibalahi A et al. $2020 \mathrm{NAD}^{+}$repletion rescues female fertility during reproductive aging. Cell Reports 30 1670.e7-1681.e7. (https://doi.org/10.1016/j. celrep.2020.01.058)

Bonkowski MS \& Sinclair DA 2016 Slowing aging by design: the rise of $\mathrm{NAD}^{+}$and sirtuin-activating compounds. Nature Reviews: Molecular Cell Biology 17 679-690. (https://doi.org/10.1038/nrm.2016.93)

Canto C, Menzies KJ \& Auwerx J 2015 NAD $^{+}$metabolism and teh control of energy homeostasis: a balancing act between mitochondria and the nucleus. Cell Metabolism 22 31-53. (https://doi.org/10.1016/j. cmet.2015.05.023)

Cozzi A, Cipriani G, Fossati S, Faraco G, Formentini L, Min W, Cortes U, Wang ZQ, Moroni F \& Chiarugi A 2006 Poly(ADP-ribose) accumulation and enhancement of postischemic brain damage in 110-kDa poly(ADPribose) glycohydrolase null mice. Journal of Cerebral Blood Flow and Metabolism 26 684-695. (https://doi.org/10.1038/sj.jcbfm.9600222)

Das A, Huang GX, Bonkowski MS, Longchamp A, Li C, Schultz MB, Kim LJ, Osborne B, Joshi S, Lu Y et al. 2018 Impairment of an endothelial $\mathrm{NAD}+-\mathrm{H}_{2} \mathrm{~S}$ signaling network is a reversible cause of vascular aging. Cell 173 74.e20-89.e20. (https://doi.org/10.1016/j.cell.2018.02.008)

Dath C, Van Eyck AS, Dolmans MM, Romeu L, Delle Vigne L, Donnez J \& Van Langendonckt A 2010 Xenotransplantation of human ovarian tissue to nude mice: comparison between four grafting sites. Human Reproduction 25 1734-1743. (https://doi.org/10.1093/humrep/deq131)

De Vos M, Smitz J \& Woodruff TK 2014 Fertility preservation in women with cancer. Lancet 384 1302-1310. (https://doi.org/10.1016/S01406736(14)60834-5)

Di Emildio G, Falone S, Vitti M, D'Alessandro AM, Vento M, Di Pietro C, Amicarelli F \& Tatone C 2014 SIRT1 signalling protects mouse oocytes against oxidative stress and is deregulated during aging. Human Reproduction 29 2006-2017. (https://doi.org/10.1093/humrep/deu160)

Dolmans MM, Martinez-Madrid B, Gadisseux E, Guiot Y, Yuan WY, Torre A, Camboni A, Van Langendonckt A \& Donnez J 2007 Short-term transplantation of isolated human ovarian follicles and cortical tissue into nude mice. Reproduction 134 253-262. (https://doi.org/10.1530/ REP-07-0131)

Donnez J \& Dolmans MM 2010 Cryopreservation and transplantation of ovarian tissue. Clinical Obstetrics and Gynecology 53 787-796. (https:// doi.org/10.1097/GRF.0b013e3181f97a55)

Donnez J \& Dolmans MM 2014 Transplantation of ovarian tissue. Best Practice and Research Clinical Obstetrics and Gynaecology 28 1188-1197. (https://doi.org/10.1016/j.bpobgyn.2014.09.003)

Donnez J \& Dolmans MM 2017 Fertility preservation in women. New England Journal of Medicine 377 1657-1665. (https://doi.org/10.1056/ NEJMra1614676) 
Eliasson MJ, Kampei K, Mandir AS, Hurn PD, Traystman RJ, Bao J, Pieper A, Wang ZQ, Dawson TM, Snyder SH et al. 1997 Poly(ADP-robose) polymerase gene disruption renders mice resistant to cerebral ischemia. Nature Medicine 3 1089-1095. (https://doi.org/10.1038/nm1097-1089)

Endres M, Wang ZQ, Namura S, Waeber C \& Moskowitz MA 1997 Ischemic brain injury is mediated by the activation of poly(ADPribose)polymerase. Journal of Cerebral Blood Flow and Metabolism 17 1143-1151. (https://doi.org/10.1097/00004647-199711000-00002)

Fang EF, Lautrop S, Hou Y, Demarest TG, Croteau DL, Mattson MP \& Bohr VA 2017 NAD $^{+}$in aging: molecular mechanisms and translational implications. Trends in Molecular Medicine 23 899-916. (https://doi. org/10.1016/j.molmed.2017.08.001)

Gao JM, Yan J, Li R, Li M, Yan LY, Wang TR, Zhao HC, Zhao Y, Yu Y \& Qiao J 2013 Improvement in teh quality of heterotopic allotranplanted mouse ovarian tissues with basic fibroblast growth factor and fibrin hydrogel. Human Reproduction 28 2784-2793. (https://doi.org/10.1093/humrep/ $\operatorname{det} 296)$

Gavish Z, Peer G, Roness H, Cohen Y \& Meirow D 2014 Follicle activation and 'burn-out' contribute to post-transplantation follicle loss in ovarian tissue grafts: the effect of graft thickness. Human Reproduction 29 989-996. (https://doi.org/10.1093/humrep/deu015)

Gavish Z, Spector I, Peer G, Schlatt S, Wistuba J, Roness H \& Meirow D 2018 Follicle activation is a significant and immediate cause of follicle loss after ovarian tissue transplantation. Journal of Assisted Reproduction and Genetics 35 61-69. (https://doi.org/10.1007/s10815-017-1079-z)

Gook DA, McCully BA, Edgar DH \& McBain JC 2001 Development of antral follicles in human cryopreserved ovarian tissue following xenografting. Human Reproduction 16 417-422. (https://doi. org/10.1093/humrep/16.3.417)

Ho WHJ, Listijono D, Bertoldo MJ, Li SYC, Youngsen N, Brady N, Kordowitzki P, Turner N, Morris MJ, Gilchrist RB et al. 2017 Protection and restoration of female fertility during gonadotoxic chemotherapy by elevating $\mathrm{NAD}^{+}$. In Proceedings of the 48th Annual Conference of the Society for Reproductive Biology, Perth, Australia.

Iljas JD, Wei Z \& Homer HA 2020 Sirt1 sustains female fertility by slowing age-related decline in oocyte quality required for post-fertilization embryo development. Aging Cell 19 e13204. (https://doi.org/10.1111/acel.13204)

Jeruss JS \& Woodruff TK 2009 Preservation of fertility in cancer patients. New England Journal of Medicine 360 902-911. (https://doi.org/10.1056/ NEJMra0801454)

Lee J, Kong HS, Kim EJ, Youm HW, Lee JR, Suh CS \& Kim SH 2016 Ovarian injury during cryopreservation and transplantation in mice: a comparative study between cryoinjury and ischemic injury. Human Reproduction 31 1827-1837. (https://doi.org/10.1093/humrep/dew144)

Liang J, Wang P, Wei J, Bao C \& Han D 2015 Nicotinamide mononucleotide adenylyltransferase 1 protects neural cells against ischemic injury in primary cultured neuronal cells and mouse brain with ischemic stroke through AMP-activated protein kinase activation. Neurochemical Research 40 1102-1110. (https://doi.org/10.1007/ s11064-015-1569-2)

Liu J, Van der Elst J, Van den Broecke R \& Dhont M 2002 Early massive follicle loss and apoptosis in heterotopically grafted newborn mouse ovaries. Human Reproduction 17 605-611. (https://doi.org/10.1093/ humrep/17.3.605)

Mahmoodi M, Mehranjani MS, Shariatzadeh SMA, Eimani H \& Shahverdi A $2015 \mathrm{~N}$-acetylcysteine improves function and follicular survival in mice ovarian grafts through inhibition of oxidative stress. Reproductive Biomedicine Online 30 101-110. (https://doi. org/10.1016/j.rbmo.2014.09.013)

Marinova MB, Ho W-HJ, Bertoldo MJ, Selesniemi K, Homer HA, Walsh WR, Sinclair DA, Walters KA, Gilchrist RB \& Wu LE 2020 NMN supplementation rescues chemotherapy induced bone ageing. In Proceedings of the Cold Spring Harbour Laboratory Mechanisms of Aging Conference.

Martinez-Madrid B, Donnez J, Van Eyck AS, Veiga-Lopez A, Dolmans MM \& Van Langendonckt A 2009 Chick embryo chorioallantoic membrane (CAM) model: a useful tool to study short-term transplantation of cryopreserved human ovarian tissue. Fertility and Sterility 91 285-292. (https://doi.org/10.1016/j.fertnstert.2007.11.026)

McCord JM 1985 Oxygen-derived free radicals in postischemic tissue injury. New England Journal of Medicine 312 159-163. (https://doi. org/10.1056/NEJM198501173120305)
Meirow D, Ra'anani H \& Biderman H 2014 Ovarian tissue cryopreservation and transplantation: a realistic, effective technology for fertility preservation. Methods in Molecular Biology 1154 455-473. (https://doi. org/10.1007/978-1-4939-0659-8_21)

Miao Y, Cui Z, Gao Q, Rui R \& Xiong B 2020 Nicotinamide mononucleotide supplementation reverses the declining quality of maternally aged oocytes. Cell Reports 32 107987. (https://doi.org/10.1016/j.celrep.2020.107987)

Mori V, Amici A, Mazzola F, Di Stefano M, Conforti L, Magni G, Ruggieri S, Raffaelli N \& Orsomando G 2014 Metabolic profiling of alternative NAD biosynthetic routes in mouse tissues. PLoS ONE 9 e113939. (https://doi. org/10.1371/journal.pone.0113939)

Myers M, Britt KL, Wreford NGM, Ebling FJP \& Kerr JB 2004 Methods for quantifying follicular numbers within the mouse ovary. Reproduction 127 569-580. (https://doi.org/10.1530/rep.1.00095)

Ortega HH, Salvetti NR \& Padmanabhan V 2009 Developmental programming: prenatal androgen excess disrupts ovarian steroid receptor balance. Reproduction 137 865-877. (https://doi.org/10.1530/ REP-08-0491)

Park JH, Long A, Owens K \& Kristian T 2016 Nicotinamide mononucleotide inhibits post-ischemic $\mathrm{NAD}^{+}$degradation and dramatically ameliorates brain damage following global cerebral ischemia. Neurobiology of Disease 95 102-110. (https://doi.org/10.1016/j.nbd.2016.07.018)

Rajman L, Chwalek K \& Sinclair DA 2018 Therapeutic potential of NADboosting molecules: the in vivo evidence. Cell Metabolism 27 529-547. (https://doi.org/10.1016/j.cmet.2018.02.011)

Roness H \& Meirow D 2019 Follicle reserve loss in ovarian tissue transplantation. Reproduction 158 F35-F44. (https://doi.org/10.1530/ REP-19-0097)

Salvetti NR, Ortega HH, Veiga-Lopez A \& Padmanabhan V 2012 Developmental programming: impact of prenatal testosterone excess on ovarian cell proliferation and apoptotic factors in sheep. Biology of Reproduction 87 22, 1-10. (https://doi.org/10.1095/ biolreprod.112.100024)

Smitz JEJ \& Cortvrindt RG 2002 The earliest stages of folliculogenesis in vitro. Reproduction 123 185-202. (https://doi.org/10.1530/ rep.0.1230185)

Stoop D, Cobo A \& Silber S 2014 Fertility preservation for age-related fertility decline. Lancet 384 1311-1319. (https://doi.org/10.1016/S01406736(14)61261-7)

Stringer J, Groenewegen E, Liew SH \& Hutt K 2020 NMN does not protect the ovarian reserve from cancer treatments. Reproduction 159 105-113. (https://doi.org/10.1530/REP-19-0337)

Tatone C, De Emilio G, Barbonetti A, Carta G, Luciano AM, Falone S \& Amicarelli F 2018 Sirtuins in gamete biology and reproductive physiology: emerging roles and therapeutic potential in female and male infertility. Human Reproduction Update 24 267-289. (https://doi. org/10.1093/humupd/dmy003)

Tuncer AA, Bozkurt HF, Koken T, Dogan N, Pektas MK \& Embleton DB 2016 The protective effects of alpha-lipoic acide and coenzyme Q10 combination on ovarian ischemia-reperfusion injury: an experimental study. Advances in Medicine 20163415046.

Usta U, Inan M, Erbas H, Aydogdu N, Puyan FO \& Altaner S 2008 Tissue damage in rat ovaries subjected to torsion and detorsion: effects of L-carnitine and $\mathrm{N}$-acetyl cysteine. Pediatric Surgery International 24 567-573. (https://doi.org/10.1007/s00383-008-2123-y)

Van Eyck AS, Jordan BF, Gallez B, Heilier JF, Van Langendonckt A \& Donnez J 2009 Electron paramagnetic resonance as a tool to evaluate human ovarian tissue reoxygenation after xenografting. Fertility and Sterility 92 374-381. (https://doi.org/10.1016/j.fertnstert.2008.05.012)

Van Eyck AS, Bouzin C, Feron O, Romeu L, Van Langendonckt A, Donnez J \& Dolmans MM 2010 Both host and graft vessels contribute to revascularization of xenograft human ovarian tissue in a murine model. Fertility and Sterility 93 1676-1685. (https://doi.org/10.1016/j. fertnstert.2009.04.048)

Walters KA, Allan CM, Jimenez M, Lim PR, Davey RA, Zajac JD, Illingworth P \& Handelsman DJ 2007 Female mice haploinsufficient for an inactivated androgen receptor (AR) exhibit age-dependent defects that resemble the AR null phenotype of dysfunctional late follicle development, ovulation, and fertility. Endocrinology 148 3674-3684. (https://doi.org/10.1210/en.2007-0248)

Wang P, Xu TY, Guan YF, Tian WW, Viollet B, Rui YC, Zhai QW, Su DF \& Miao CY 2011 Nicotinamide phosphoribosyltransferase protects against 
ischemic stroke through SIRT1-dependent adenosine monophosphateactivated kinase pathway. Annals of Neurology 69 360-374. (https://doi. org/10.1002/ana.22236)

Wei CC, Kong YY, Hua X, Li GQ, Zheng SL, Cheng MH, Wang P \& Miao CY 2017 NAD replenishment with nicotinamide mononucleotide protects blood-brain barrier integrity and attenuates delayed tissue plasminogen activator-induced haemorrhagic transformation after cerebral ischaemia. British Journal of Pharmacology 174 3823-3836. (https://doi.org/10.1111/bph.13979)

Yamamoto T, Byun J, Zhai P, Ikeda Y, Oka S \& Sadoshima J 2014 Nicotinamide mononucleotide, an intermediate of $\mathrm{NAD}^{+}$synthesis, protects the heart from ischemia and reperfusion. PLOS ONE 9 e98972. (https://doi.org/10.1371/journal.pone.0098972)

Yang Q, Cong L, Wang Y, Luo X, Li H, Wang H, Zhu J, Dai S, Jin H, Yao G et al. 2020 Increasing ovarian $\mathrm{NAD}^{+}$levels improve mitochondrial functions and reverse ovarian aging. Free Radical Biology and Medicine 156 1-10. (https://doi.org/10.1016/j.freeradbiomed.2020.05.003)

Zhang Y, Xia X, Yan J, Yan L, Lu C, Zhu X, Wang T, Yin T, Li R, Chang HM et al. 2017 Mesemchymal stem cell-derived angiogenin promotes primordial follicle survival and angiogenesis in transplanted human ovarian tissue. Reproductive Biology and Endocrinology 15 18. (https:// doi.org/10.1186/s12958-017-0235-8)

Received 29 September 2020

First decision 5 November 2020

Revised Manuscript received 1 December 2020

Accepted 15 December 2020 